\title{
Multi-layered Barium and Strontium Carbonate Structures Induced by the Small Organic Dye Acid Orange 7
}

\author{
Ariane V. Mader, Lukas Helmbrecht, and Willem L. Noorduin*
}

Cite This: Cryst. Growth Des. 2021, 21, 6349-6356

Read Online

ABSTRACT: The crystal growth behavior induced by small molecular additives is commonly assumed to be far less complex and rich in comparison to that obtained when using macromolecules. Herein, we demonstrate that the small organic molecule Acid Orange 7 can induce a large diversity of multi-layered barium carbonate structures. These multi-layered structures stem from the small molecule imperfectly blocking the fastest growing crystal face. By tuning the balance of growth and inhibition, we control the layer shape and thickness of the structures. Extending these strategies to strontium carbonate enables the precipitation of large quasi two-dimensional multi-layer sheets. Collectively, these findings highlight the unforeseen potential for using small organic molecules to induce the formation of complex inorganic structures.

\section{INTRODUCTION}

The superior properties of naturally occurring multi-layered materials in comparison to their bulk counterparts have inspired various attempts and approaches to synthesize such structures. $^{1-5}$ Layer-by-layer techniques create highly regular materials but require the repetition of precisely controlled steps. ${ }^{6-14}$ Alternatively, organic molecules have been used to induce multi-layered crystal growth in a single step. ${ }^{2,13,15-27}$ The introduction of organic additives is a common strategy for controlling crystal orientation, shape, size, and polymorphism, as well as nucleation and growth behavior. This control often stems from favorable interactions of the additive with specific crystal faces, which is greatly affected by the functional groups of the molecule.

Dye molecules are especially well known and studied to affect growing crystals. ${ }^{28,29}$ However, the effects of these small molecules appear limited in comparison to those of macromolecules, such as polymers and proteins. The greater size of macromolecules leads to stronger noncovalent adsorption and perturbing effects and can promote crystal aggregation. Consequently, it is generally assumed that macromolecules enable much richer crystal growth behavior, including multilayered crystal growth, in comparison to smaller molecules. ${ }^{30,31}$ Due to the omnipresence of small molecules, however, it is fundamentally important to understand their role in biologically controlled multi-layer formation. Moreover, since small molecules are oftentimes relatively simple to synthesize, this may open new practical routes for the fabrication of artificial multi-layered materials.

Herein, we explore how small molecules can induce complex crystal growth modes, including multi-layer growth. To this

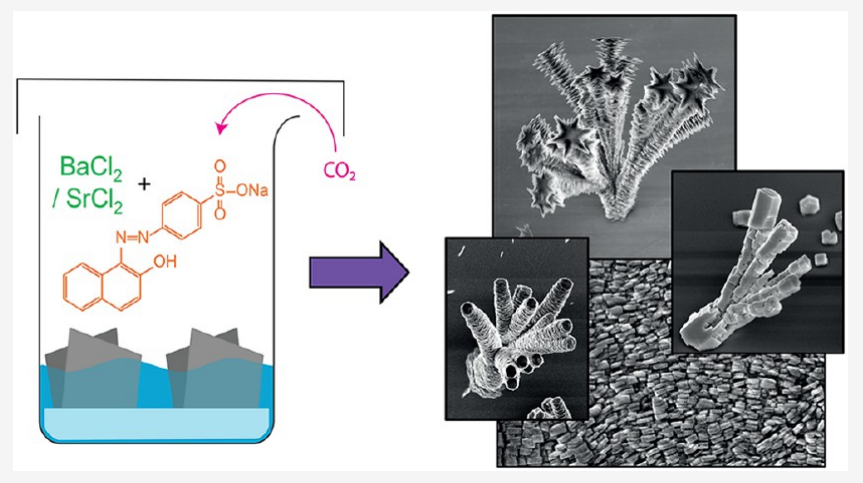

aim, we use a water-soluble dye ${ }^{32}$ functionalized with chemical groups such as a sulfonate group, ${ }^{33,34}$ allowing for a strong interaction with crystal surfaces of alkaline earth metal carbonates. Specifically, barium carbonate $\left(\mathrm{BaCO}_{3}\right)$ is a suitable metal carbonate, as it exclusively forms the mineral witherite under standard conditions. ${ }^{35,36}$ Barium compounds are also known to strongly interact with sulfonate groups, as they are commonly used to remove sulfates from water. ${ }^{37-42}$ While various simple witherite morphologies have been achieved with the use of additives, ${ }^{43-57}$ no multi-layer morphologies have been reported to the best of our knowledge. In spite of this, we expect that the interaction of a suitable small sulfonated dye molecule with witherite will lead to drastic changes in the final crystal morphology.

Based on this rational, we investigate the influence of the sulfonated organic dye Acid Orange 7 (AO7) on the crystallization of $\mathrm{BaCO}_{3}$. We observe that $\mathrm{AO} 7$ has a strong effect on crystallization, inducing the growth of a plethora of multi-layer structures. Exploiting intrinsic parameter gradients in our experiments, we investigate the effect of subtle condition changes on the final crystal morphology and composition. While macromolecules are well known for causing dramatic changes in crystal growth, we show that small molecules can

Received: July 21, 2021

Revised: September 15, 2021

Published: September 28, 2021 


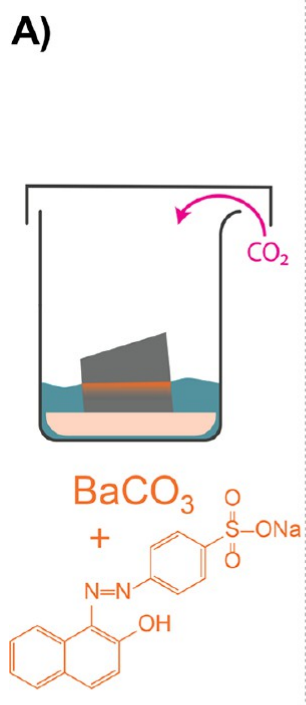

B) $\quad 0 \mathrm{mM} \mathrm{AO7}$

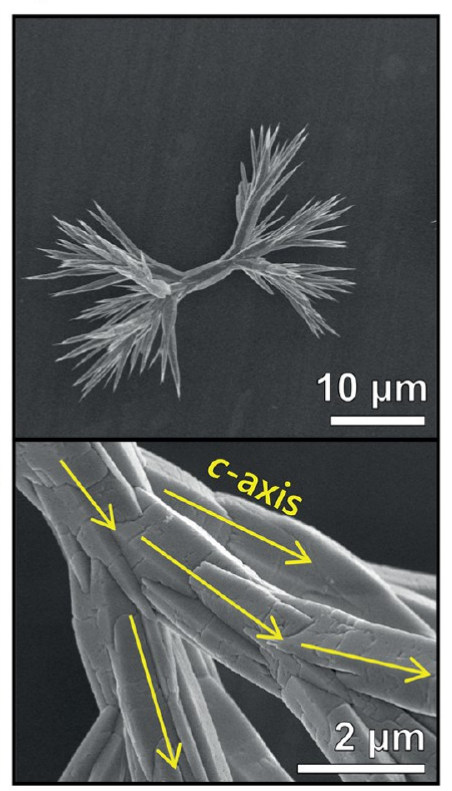

$0.25 \mathrm{mM} \mathrm{AO7}$

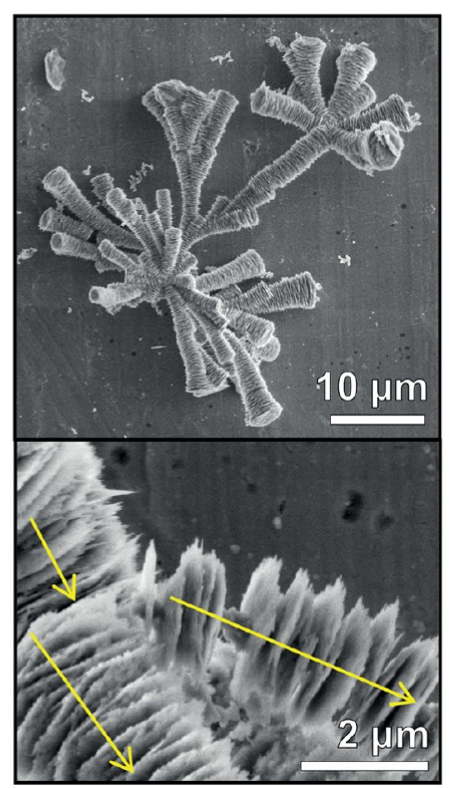

$0.75 \mathrm{mM} \mathrm{AO7}$

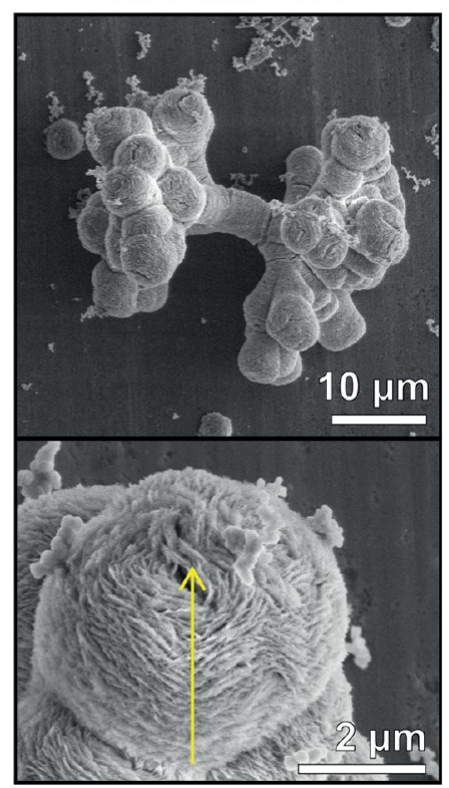

Figure 1. Effect of AO7 on the growth of witherite crystals. (A) Schematic of the experiment. The structures grow on a substrate placed vertically in a reaction solution using a sample holder. (B) SEM images of witherite crystals grown in the presence of different AO7 concentrations, resulting in a transition from typical smooth spherulitic $\mathrm{BaCO}_{3}$ crystals to segmented plates stacked along the crystallographic $c$-axis. Arrows indicate the $c$-axis direction of individual branches.

also induce a rich diversity of morphologies, including multilayered structures.

\section{RESULTS AND DISCUSSION}

We precipitate $\mathrm{BaCO}_{3}$ in the presence and absence of $\mathrm{AO} 7$ and compare the resulting structures. For this, we make an aqueous basic $(11<\mathrm{pH}<12)$ solution containing $\mathrm{BaCl}_{2}(20.2$ $\mathrm{mM})$ and different concentrations of $\mathrm{AO} 7(0.00,0.25,0.50$, 0.75 , and $1.00 \mathrm{mM}$ ) and let the $\mathrm{CO}_{2}$ of the air diffuse into the solution to prompt the $\mathrm{BaCO}_{3}$ precipitation (see Experimental Procedure for details, Figure 1A). After $1.5 \mathrm{~h}$, we terminate the growth and investigate the shape and dye incorporation of the microstructures using scanning electron microscopy (SEM) and energy-dispersive X-ray spectroscopy (EDS), respectively. In the absence of $\mathrm{AO} 7$, witherite grows in the expected shape of smooth spherulitic crystals with a pseudo-hexagonal shape in the $c$-plane and main growth direction and branching along the $c$-axis (Figure 1B). Grown in the presence of AO7, the overall spherulitic shape is preserved, but closer inspection reveals that the structure consists of many aligned plates with diameters of ca. 3-6 $\mu \mathrm{m}$. The plates extend along the $c$-plane and are stacked along the $c$-axis, giving the overall appearance of the spherulitic branches. Thus, even a small concentration of dye $(0.25 \mathrm{mM})$ already leads to a drastic transformation of the crystal surface from smooth to segmented.

The segmentation of the structures indicates that the dye interacts strongest with the (001) crystal surface, thereby retarding the growth along the $c$-axis. Consistent with this rational, we observe that an increase in $\mathrm{AO} 7$ leads to structures with more segmentation (Figure 1B). In addition, it appears that an increase in dye concentration leads to non-crystallographic alignment of the formed plates, also termed small-angle branching. This branching is commonly induced by the presence of impurities such as dyes, which introduce crystal defects leading to a slight crystallographic misalignment of the next crystal layer. ${ }^{58}$ The spherulitic growth caused by this misalignment can be observed well at the round ends of the structures, as well as by the formation of almost spherical smaller shapes (Supporting Information Figure S1). Moreover, EDS analysis shows that the dye incorporation into the structures also increases from ca. 5 at. \% dye at $0.25 \mathrm{mM} \mathrm{AO7}$ to ca. 12 at. \% dye at $1 \mathrm{mM} \mathrm{AO7.} \mathrm{Increasing} \mathrm{dye} \mathrm{concentration}$ in the solution thus leads to increased dye incorporation, increased segmentation, and small-angle branching in the final structure.

Small molecules can retard specific crystal growth directions by selectively adsorbing to crystal faces. ${ }^{28}$ Here, it appears that the (001) face is recurrently blocked, while the other crystal faces remain unaffected. The (001) witherite face is polar and can be either positively or negatively charged. ${ }^{49}$ The dye, on the other hand, is negatively charged under the basic experimental conditions, so it can adsorb well to this crystal face. Sulfate and sulfonate groups have also been reported to interact with the (001) face of calcite specifically ${ }^{15,18,59-61}$ because their tridentate arrangement allows for the imitation of the oxygen positions incorporated into this crystal face as part of the carbonate anions. ${ }^{61}$ Overall, this suggests that the multilayer growth could stem from a selective adsorption of the dye onto the fastest growing crystal face, thereby causing selective blocking.

To test the hypothesis that the segmented growth stems from the dye blocking the (001) crystal face, we perform a two-step crystallization experiment: (i) witherite is grown in the presence of $\mathrm{AO} 7$ for $10 \mathrm{~min}$ and the created structures are then characterized using SEM and (ii) the same structures are immersed into a fresh witherite growth solution without AO7 and subsequently re-imaged for a direct comparison. After step (i), we find-as expected-that the structures are composed of plates that are stacked along the $c$-axis. After step (ii), in the absence of the dye, the growth of the existing structures 

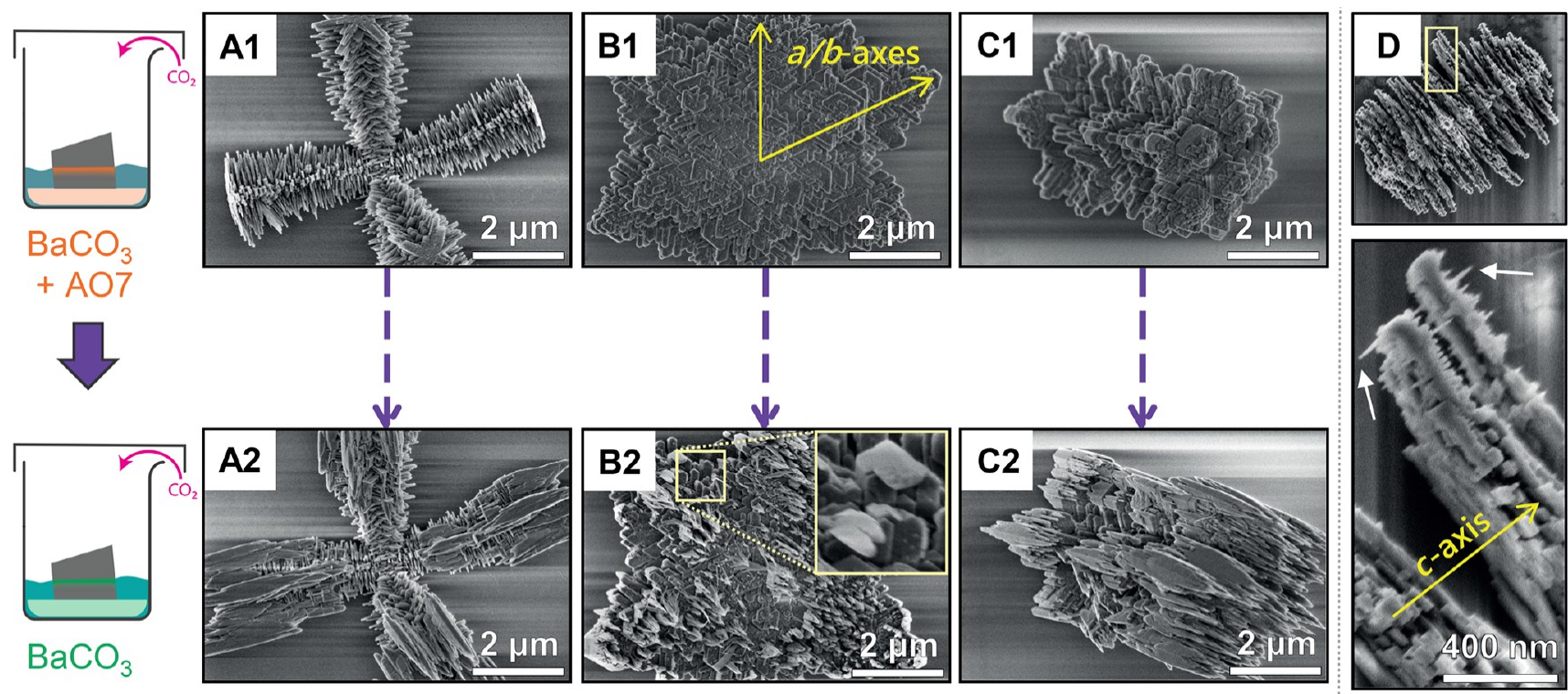

Figure 2. Blocking effect of $\mathrm{AO} 7$ on the growth of witherite. SEM images of different structures $(\mathrm{A}-\mathrm{C})$ were taken after 10 min growth of witherite in the presence of $0.25 \mathrm{mM} \mathrm{AO} 7$ (1). After subsequent growth for another $10 \mathrm{~min}$ in the absence of $\mathrm{AO} 7$, the same structures were reimaged (2). Oriented nucleation of $\mathrm{BaCO}_{3}$ crystals occurs on the edges of the original structure and not on the (001) faces. This suggests that the (001) faces are blocked, whereas the edges remain uninhibited. (D) Structure grown in the presence of AO7 for 10 min. The zoom in of the marked area shows the overall growth in the $c$-direction being blocked, but mineral bridges growing from a few spots (indicated by white arrows), enabling the formation of another layer extending in the $c$-plane.

continues fastest in the $c$-axis direction typical for witherite growth (Figure 2). Moreover, the nucleation in step (ii) adopts the crystallographic orientation of the initial structure and mainly occurs at the crystal edges, which have just grown in step (i) and are therefore likely not yet inhibited by the dye. Collectively, these findings suggest that the dye imperfectly but permanently blocks the (001) face, thereby relatively enhancing the growth in the $c$-plane.

We study the early stages of growth to gain further insights into the mechanism of the plate formation. Structures grown for only 10 min reveal small arms on the (001) face reaching in the $c$-axis direction (Figure 2D). These arms likely stem from uninhibited spots on the surface and can subsequently act as mineral bridges to mediate the growth of the next plate-like layer of the structure. Additionally, such mineral bridges may be caused by the supersaturation build-up from the growth inhibition, which decreases the critical size of the nucleus. ${ }^{62}$ Both mechanisms can explain the mineral bridge formation, which indicates that the plate-like AO7-induced structures are not assembled from separate plates but rather grown in a staircase-like manner.

To elucidate the parameters affecting this blocking mechanism, we investigate how the structure growth adjusts to different growth conditions. Specifically, we systematically ascertain the influence of the $\mathrm{pH}$ and $\mathrm{CO}_{2}$ concentration on the growth of witherite in the presence of AO7. To avoid complications from nucleation inhibition, we use pre-grown witherite seeds. The growth of these seeds is subsequently continued in the presence of $\mathrm{AO} 7$ using a starting $\mathrm{pH}$ of 11.3 (low), 11.8 (medium), or 12.1 (high). The seeds are positioned on a vertical sample slide in the solution, and atmospheric $\mathrm{CO}_{2}$ is entering at the meniscus (Figure 3A). Effectively, this setup creates a continuous vertical gradient of $\mathrm{CO}_{2} \cdot{ }^{63}$ Furthermore, the witherite formation releases $\mathrm{H}^{+}$ions, following the simplified reaction $\mathrm{Ba}^{2+}+\mathrm{CO}_{2}+\mathrm{H}_{2} \mathrm{O} \rightarrow \mathrm{BaCO}_{3}$ $+2 \mathrm{H}^{+}$, which makes the local environment around the growing structures more acidic. ${ }^{64}$ Hence, by vertically analyzing the samples, we can perform a combinatorial screening of the influence of $\mathrm{pH}$ and $\mathrm{CO}_{2}$ on the growth of witherite in the presence of AO7.

Vertically screening the samples with SEM reveals a plethora of gradually altering, yet distinct structures that can be classified according to two main features: the spatial segmentation frequency and the (001) face or plate shape (Figure 3). Decoupling of nucleation and growth gives more detailed insights into the effect of $\mathrm{AO} 7$ on the mineralization process. Specifically, we observe an interlaced growth of layers, consistent with the expected staircase-like growth stemming from mineral bridge formation (Figure 3B).

We also find that the spatial segmentation frequency of the structures, exhibiting $<0.1-2 \mu \mathrm{m}$ thick segments, follows a trend within and between experiments. Deeper in the solution, where the $\mathrm{CO}_{2}$ concentration is lower, the segmentation frequency of the structures increases (Figure 4). An increased segmentation frequency is also observed for a lower bulk $\mathrm{pH}$. Additionally, EDS analysis reveals that an increased segmentation frequency correlates with a greater AO7 incorporation, which is in agreement with the dye induced blocking mechanism (Figure 4B). These observations suggest that the segmentation frequency is determined by the growth rate, which slows down for decreased $\mathrm{pH}$ and lower $\mathrm{CO}_{2}$ concentration. Consequently, a slower growth rate is expected to amplify the effect of AO7, as it allows for greater dye adsorption, which in turn increases the segmentation frequency.

To verify the hypothesis that the witherite growth rate is the main influence on the segmentation frequency, we modulate the $\mathrm{CO}_{2}$ influx - and thereby the witherite growth rate-in the presence of $\mathrm{AO} 7$. We find that the less $\mathrm{CO}_{2}$ is allowed to reach the solution, the slower the witherite grows and the more segmentation is observed (Figure S3). Hence, these results 
A)
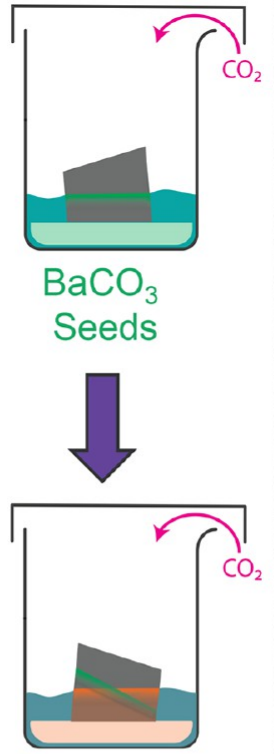

Overgrowth:

$\mathrm{BaCO}_{3}$ $+\mathrm{AO} 7$<smiles>C1CCCC1</smiles>
Intersection

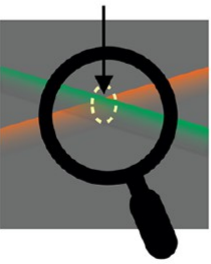

B)

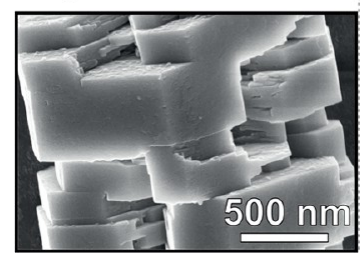

C)

\section{Solution Depth}

Meniscus +

$-0.4 \mathrm{~mm}-$

$-0.6 \mathrm{~mm}+$

pH 11.3

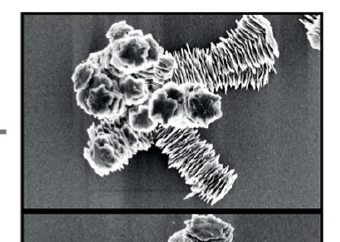

$-0.2 \mathrm{~mm}+$

$-0.8 \mathrm{~mm}+$

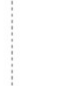

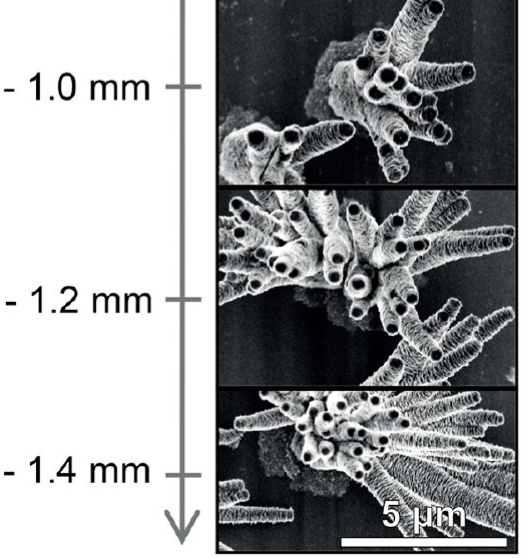

pH 11.8
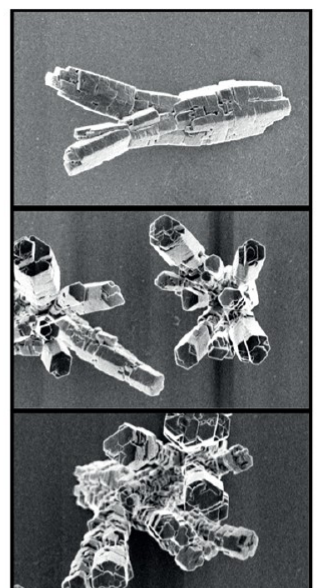

is

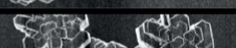

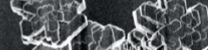

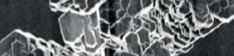

c. 3an 15

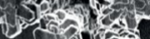

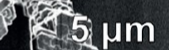

( $5 \mu \mathrm{m}$
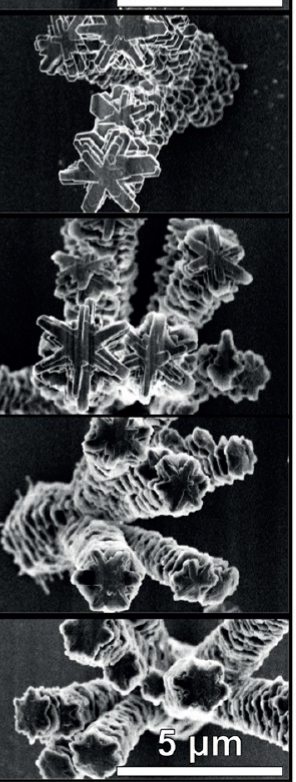

pH 12.1

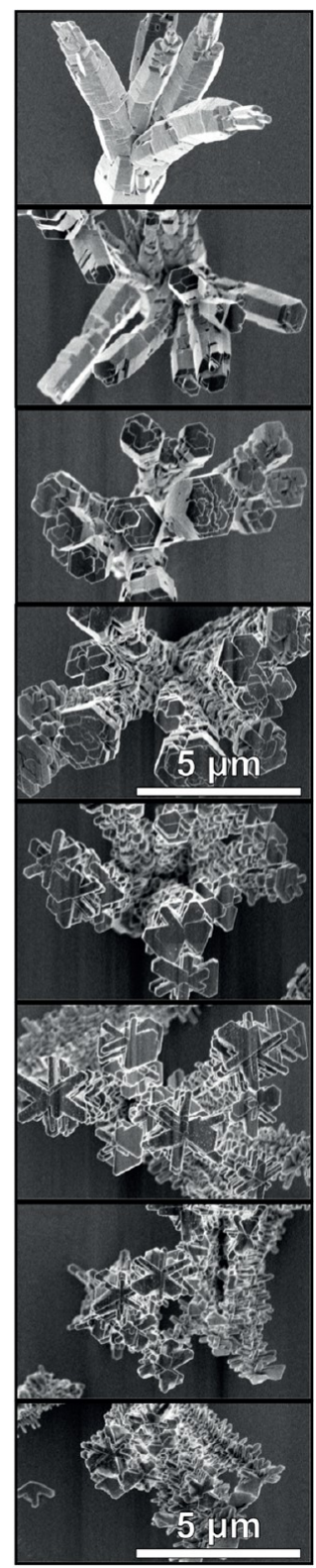

Figure 3. Variation of morphological features displayed by witherite crystals grown in the presence of AO7. (A) Schematic for the cross-growth experiments: witherite seeds were grown, and subsequently overgrown with witherite in the presence of AO7. The marked area at the intersection of these phases was investigated. (B) Stacked plate appearance stems from an interlaced growth, as opposed to the actual separate plates. (C) SEM images of crystal structures from cross-growth experiments at different starting $\mathrm{pH}$ values $(11.3,11.8$, and 12.1). Images at the top are taken approximately at the meniscus, each consecutive lower picture is of a structure grown about $0.2 \mathrm{~mm}$ deeper in the solution orthogonal to the meniscus of the overgrowth solution. Images in the same row stem from approximately the same solution depth, and all images are of the same magnification.

confirm that the effect of $\mathrm{AO} 7$ on the segmentation frequency is magnified by a lower witherite growth rate.

At the intermediate $\mathrm{pH}$ of 11.8, the overall (001) face shape progresses from strictly hexagonal plates close to the meniscus, over six-armed star-shaped, to roughly hexagonal and finally round plates deeper in the solution. A similar shape progression is found for different bulk $\mathrm{pH}$ values, albeit shifted: for the lower bulk $\mathrm{pH}$, the shapes are already starshaped at the meniscus, while for the higher bulk $\mathrm{pH}$, the shapes are of the strictly hexagonal and dendritic star type for an extended solution depth. Moreover, the shape trend coincides with the segmentation frequency trend-structures possessing a similar plate shape also have a similar segmentation frequency and $\mathrm{AO} 7$ content (Figure S4).

We assume that $\mathrm{AO} 7$ gives rise to the (001) face shape progression by affecting the local supersaturation. Close to the meniscus, the global supersaturation is great and only little (001) face blocking occurs, so the witherite plates can form in their hexagonal equilibrium morphology. Deeper in solution, a greater blocking of the (001) face increases segmentation frequency and thereby the local supersaturation for $c$-plane growth perpendicular to the main growth axis. The local 


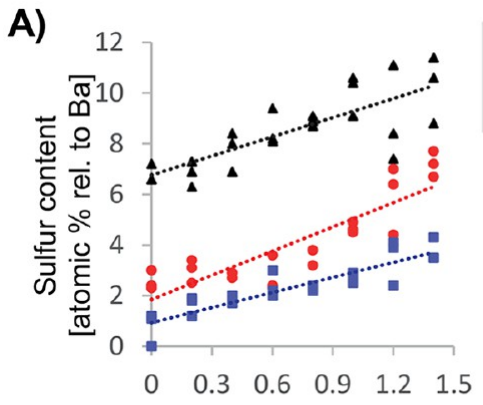

Depth from Meniscus [mm]

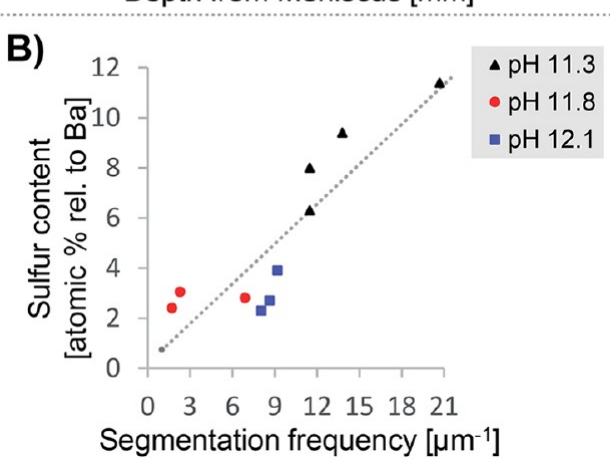

C)

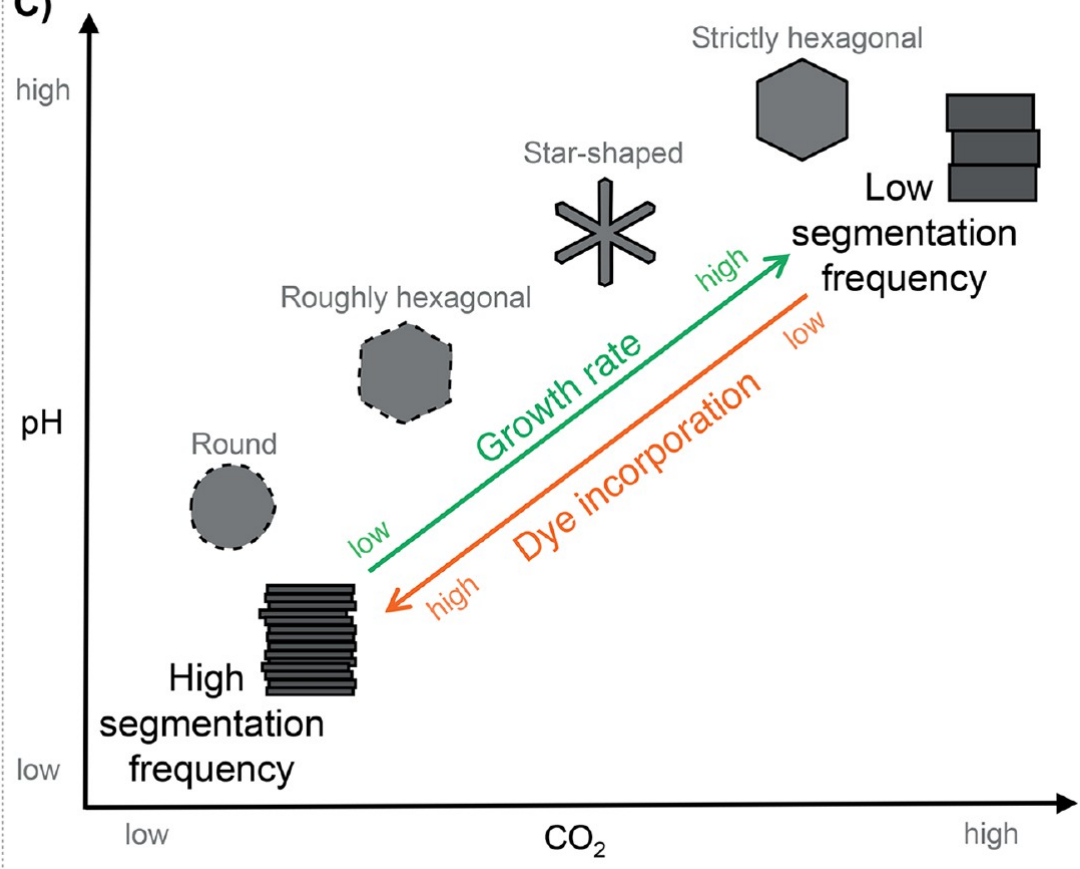

Figure 4. Effect of different parameters on the spatial segmentation frequency and plate shape of witherite structures grown in the presence of AO7. (A) Sulfur content of structures grown in the presence of AO7 increases with increasing solution depth. The dotted line serves as a guide for the eye. (B) Sulfur content of structures grown in the presence of AO7 correlates with their segmentation frequency. The dotted line serves as a guide for the eye. (C) Schematic drawing of the parameter interplay causing the observed morphology trends.

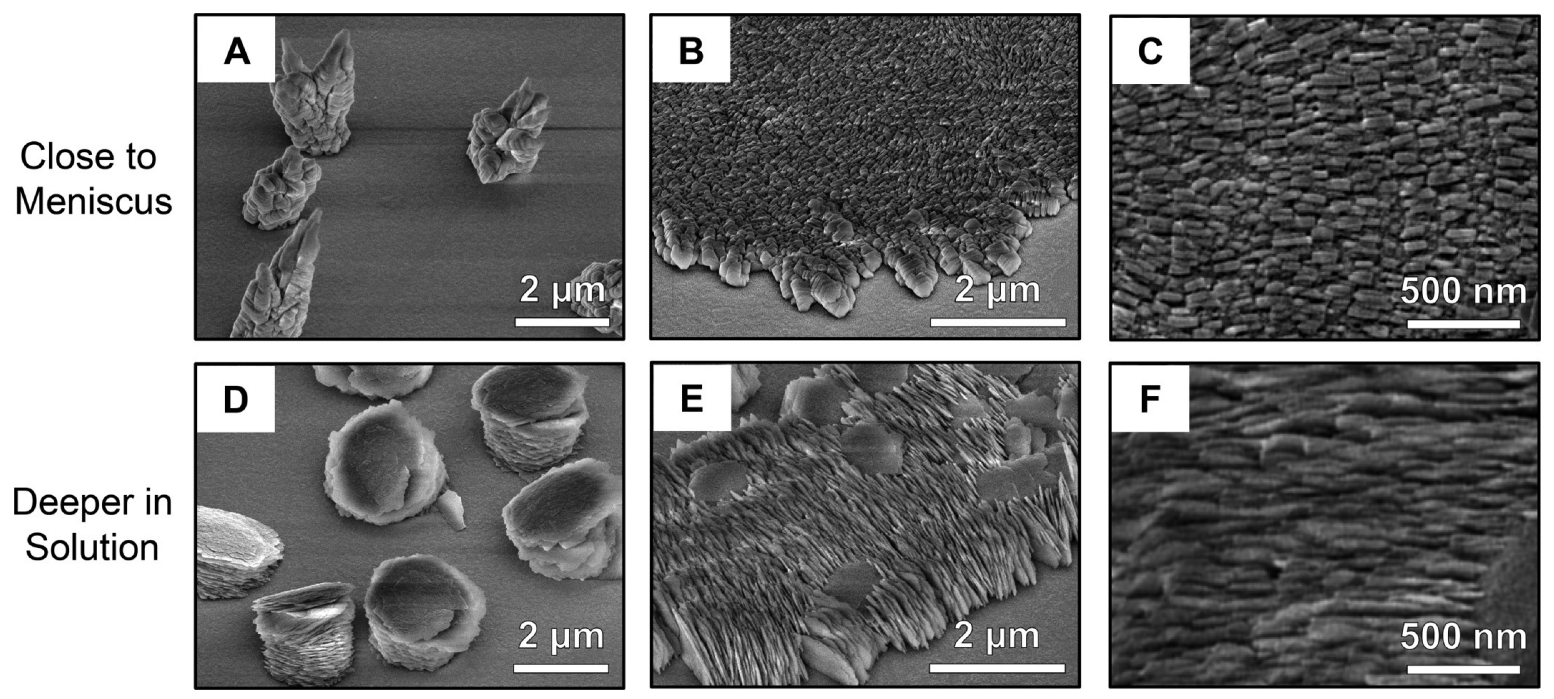

Figure 5. Multi-layered strontium carbonate structures. $(A+B+C)$ Different strontium carbonate structures found close to the meniscus, $(C)$ shows a zoom-in image of the structure (B). $(D+E+F)$ Different strontium carbonate structures grown deeper in the solution with greater segmentation frequency, $(\mathrm{F})$ shows a zoom-in image of structure $(\mathrm{E})$.

supersaturation is lower at this distance from the meniscus, causing diffusion-limited growth. Together, these effects can cause $2 \mathrm{D}$ dendritic shapes-the corners of the hexagons are transformed into the six arms of the dendritic stars (Figure S5). This is consistent with diffusion-limited growth observed for snowflakes and other crystals, including calcite, in which the corners of the crystal faces, as well as any other protrusions, are amplified. ${ }^{65-68}$ Even deeper in solution, the plates transition to hexagonal shapes again. There, the supersaturation is low globally. While the blocking is great, which locally enhances supersaturation, the overall supersaturation is still insufficient for inducing dendritic growth. The hexagonal equilibrium shape is attained, and at even lower global supersaturation, the plates are round. Therefore, we conclude that the interplay of diffusion-limited growth, global depth-related supersaturation, and local AO7-regulated supersaturation causes the (001) face shape trend (Figure 4C).

We explore the generality of small organic molecules inducing multi-layered mineralization. To this aim, we test the effect of $\mathrm{AO} 7$ on strontium carbonate, which has the same crystal structures as barium carbonate. Indeed, we find similar multi-layer structures with similar morphology trends: thick 
faceted plates close to the meniscus and thin round plates deeper in the solution (Figure 5). Moreover, we observe dense quasi two-dimensional areas of stacked strontium carbonate plates reminiscent of naturally occurring nacre. The nucleation and $c$-axis growth of these sheets proceed normal to the substrate surface, and the plate shape follows the same morphological trend as the other structures. This shows that the small organic molecule can induce quasi one-dimensional plate stacks in similar minerals and even create more complex segmented two-dimensional materials.

In this paper, we demonstrated that small organic molecules can induce highly regular multi-layer growth by imperfectly blocking the fastest growing crystal face. ${ }^{69}$ Exploiting a multivariant space, we elucidate the drastic impact of small environmental changes on the interplay between the organic molecule and the mineralization process. Based on these insights, we can tune the activity of the organic molecule on the mineralization process, thereby modulating features such as layer shape and thickness and giving rise to a rich diversity of structures.

Already, many complex mineral shapes have been synthesized by introducing organic additives. Specifically, multi-layer structures of $\mathrm{CaCO}_{3}$ have been formed, but the proposed formation mechanism involves aggregation and relies on the direction of macromolecular additives. ${ }^{15,16,18-21,23}$ Potassium sulfate crystals can also assemble in multi-layers via mineral bridges, but macromolecules have been essential for inhibiting the growth. ${ }^{17,27}$ In contrast, our results highlight that small molecules, which have previously gained little attention, can induce multi-layered growth.

We observe that our multi-layered materials possess some notable similarities to the structure of nacre: specifically, the size, thickness, shape, arrangement, and crystallographic packing and orientation of the plates. ${ }^{2,72}$ In addition, mineral bridges connecting the plates appear to play an essential role during the growth of both. ${ }^{73}$ Recent studies also suggest that many mollusks control mineral growth kinetics to direct the formation of the ultrastructure in their shells, even including transitions between ultrastructures, ${ }^{74}$ similarly to the kinetic control we have used in our experiments. This curious comparison of our structures to those created in nature emphasizes that the role of small organic molecules should be considered in the creation of both synthetic and natural layered materials.

Many intriguing questions for future research still remain. In particular, we foresee that following the growth process in situ at microscopic length scales can help to further elucidate the growth mechanism of segmentation and plate shape formation. Moreover, computational modeling to obtain further atomistic insights can shed light on how and why the dye interacts with specific crystal faces. From a practical perspective, we see the potential to grow complex multi-dimensional layered materials using simple small organic molecules, ultimately paving the way to next-generation advanced materials with new and unexplored functionalities.

\section{EXPERIMENTAL PROCEDURE}

Materials. All chemicals were used as purchased. Barium chloride dihydrate (ACS reagent, $\geq 99$ ) was purchased from Sigma-Aldrich. AO7 (Orange II, grade pure, min. $85 \%$ dye content) was purchased from Thermo Fisher Acros Organics. All reactions were performed in deionized water $(7 \mu \mathrm{S} / \mathrm{cm})$ previously purged with $\mathrm{N}_{2}$ for at least $2 \mathrm{~h}$ before use. The crystals were either grown on aluminum $(0.3 \mathrm{~mm}$ thickness, 99\% purity, GoodFellow) or glass (1 mm thickness, Menzel Gläser microscope slides, Thermo Scientific) sample slides.

Crystal Growth. The effect of the dye on witherite growth was tested by adding different dye concentrations $(0.25,0.5,0.75$, and 1 $\mathrm{mM}$ ) of $\mathrm{AO} 7$ to the witherite growth solution. The standard growth reaction was conducted in $15 \mathrm{~mL}$ of an aqueous solution containing $20.2 \mathrm{mM} \mathrm{BaCl}$ and the respective dye concentration added in $3 \mathrm{~mL}$ of water. For each concentration, the witherite growth was conducted at a starting $\mathrm{pH}$ around 11.3 and 11.8 , respectively, before dye addition. The $\mathrm{pH}$ was raised using $1 \mathrm{M} \mathrm{NaOH}$ and a Mettler Toledo FE20 FiveEasy pH meter.

Sample plates were positioned vertically in the fully prepared reaction solution. The reaction beaker was covered with a Petri dish to allow for limited $\mathrm{CO}_{2}$ influx through the spout. The reactions were terminated after $1.5 \mathrm{~h}$ by removing the sample slides from the reaction solution. Subsequently, the slides were washed with water and acetone and air-dried before analysis.

Several adaptations of the standard experiment were conducted, for which a concentration of $0.25 \mathrm{mM} \mathrm{AO} 7$ was used unless noted otherwise. For cross-growth experiments, witherite in the absence of the dye was first grown on the sample slides for $45 \mathrm{~min}$. Subsequently, the sample slide was transferred to a witherite solution containing the dye for the final $45 \mathrm{~min}$ of the reaction. Inducing a right or left tilt to the sample relative to the first growth phase led to the formation of a cross-shaped region of structures. Each line of the cross stems from one of the growth phases and at the intersection growth from both reaction solutions occurred.

Experiments for growing strontium carbonate were conducted in the same manner as above by replacing $\mathrm{BaCl}_{2}$ with $21 \mathrm{mM} \mathrm{SrCl}_{2}$.

Sputter Coating of Glass Slides. To image the structures grown on glass substrates for SEM, the glass plate was coated using a Leica EM ACE600 [version 01.01.19 (08)] high-vacuum sputter coater after the growth of the structures. The coating consisted of a $5 \mathrm{~nm}$ thick chromium or gold layer sputtered from a $50 \mathrm{~mm}$ working distance and with $4 \mathrm{rpm}$.

Sample Analysis. A Verios 460 SEM from FEI with an xT Microscope Control v5.5.2 build 3322 was used to take comparative images of the microarchitectures on the chosen sample slides; $5 \mathrm{kV}$, 50 or $100 \mathrm{pA}$, and a resolution of at least $1536 \times 1024$ were used to obtain these images. Crystallographic directions were assigned by visual appearance, making use of the characteristic interfacial angles of the pseudo-hexagonal growth of orthorhombic witherite.

An X-Max 80 (Oxford Instruments) was used with $10-20 \mathrm{kV}$ and 0.8-1.6 $\mathrm{nA}$ for the EDS analysis of characteristic structures to quantify the incorporation of the dye. The software AZtec 2.4 (Oxford Instruments) was used to interpret the collected EDS data. The EDS point and ID data of entire structures was acquired, and the atomic $\%$ of the present elements was determined. The elements used to quantify the dye and witherite content were sulfur and barium, respectively.

\section{ASSOCIATED CONTENT}

\section{Supporting Information}

The Supporting Information is available free of charge at https://pubs.acs.org/doi/10.1021/acs.cgd.1c00823.

Experimental details for structures used in figures, more detailed report of structures found, evidence of the $\mathrm{CO}_{2}$ series experiment, images for additional mechanistic clues, comparison of the morphology of structures with a similar sulfur content from the experiments of different starting pHs, and additional mechanistic cues (PDF)

\section{AUTHOR INFORMATION}

\section{Corresponding Author}

Willem L. Noorduin - AMOLF, 1098 XG Amsterdam, The Netherlands; ○ orcid.org/0000-0003-0028-2354;

Email: W.Noorduin@amolf.nl 


\section{Authors}

Ariane V. Mader - AMOLF, 1098 XG Amsterdam, The Netherlands

Lukas Helmbrecht - AMOLF, 1098 XG Amsterdam, The Netherlands

Complete contact information is available at:

https://pubs.acs.org/10.1021/acs.cgd.1c00823

\section{Author Contributions}

A.V.M. contributed to conceptualization, methodology, investigation, data curation, writing-original draft, and visualization. L.H. contributed to conceptualization, writing-review and editing, and supervision. W.L.N. contributed to conceptualization, writing-review and editing, and supervision.

\section{Notes}

The authors declare no competing financial interest.

\section{ACKNOWLEDGMENTS}

This work was part of the Vernieuwingsimpuls Vidi research program "Shaping up materials" with project number 016.Vidi.189.083, which is partly financed by the Dutch Research Council (NWO).

\section{REFERENCES}

(1) Wegst, U. G. K.; Bai, H.; Saiz, E.; Tomsia, A. P.; Ritchie, R. O. Bioinspired Structural Materials. Nat. Mater. 2015, 14, 23-36.

(2) Yao, H.-B.; Ge, J.; Mao, L.-B.; Yan, Y.-X.; Yu, S.-H. 25th Anniversary Article: Artificial Carbonate Nanocrystals and Layered Structural Nanocomposites Inspired by Nacre: Synthesis, Fabrication and Applications. Adv. Mater. 2014, 26, 163-188.

(3) Eder, M.; Amini, S.; Fratzl, P. Biological Composites-Complex Structures for Functional Diversity. Science 2018, 362, 543-547.

(4) Espinosa, H. D.; Rim, J. E.; Barthelat, F.; Buehler, M. J. Merger of Structure and Material in Nacre and Bone - Perspectives on de Novo Biomimetic Materials. Prog. Mater. Sci. 2009, 54, 1059-1100.

(5) Zhao, H.; Yang, Z.; Guo, L. Nacre-Inspired Composites with Different Macroscopic Dimensions: Strategies for Improved Mechanical Performance and Applications. NPG Asia Mater. 2018, 10, 1-22.

(6) Finnemore, A.; Cunha, P.; Shean, T.; Vignolini, S.; Guldin, S.; Oyen, M.; Steiner, U. Biomimetic Layer-by-Layer Assembly of Artificial Nacre. Nat. Commun. 2012, 3, 966.

(7) Yao, H.-B.; Fang, H.-Y.; Tan, Z.-H.; Wu, L.-H.; Yu, S.-H. Biologically Inspired, Strong, Transparent, and Functional Layered Organic-Inorganic Hybrid Films. Angew. Chem. 2010, 122, 21862191.

(8) Podsiadlo, P.; Kaushik, A. K.; Arruda, E. M.; Waas, A. M.; Shim, B. S.; Xu, J.; Nandivada, H.; Pumplin, B. G.; Lahann, J.; Ramamoorthy, A.; et al. Ultrastrong and Stiff Layered Polymer Nanocomposites. Science 2007, 318, 80-83.

(9) Han, J.; Dou, Y.; Yan, D.; Ma, J.; Wei, M.; Evans, D. G.; Duan, X. Biomimetic Design and Assembly of Organic-Inorganic Composite Films with Simultaneously Enhanced Strength and Toughness. Chem. Commun. 2011, 47, 5274-5276.

(10) Podsiadlo, P.; Michel, M.; Lee, J.; Verploegen, E.; Wong Shi Kam, N.; Ball, V.; Lee, J.; Qi, Y.; Hart, A. J.; Hammond, P. T.; et al. Exponential Growth of LBL Films with Incorporated Inorganic Sheets. Nano Lett. 2008, 8, 1762-1770.

(11) Priolo, M. A.; Gamboa, D.; Holder, K. M.; Grunlan, J. C. Super Gas Barrier of Transparent Polymer-Clay Multilayer Ultrathin Films. Nano Lett. 2010, 10, 4970-4974.

(12) Yang, Y.-H.; Bolling, L.; Priolo, M. A.; Grunlan, J. C. Super Gas Barrier and Selectivity of Graphene Oxide-Polymer Multilayer Thin Films. Adv. Mater. 2013, 25, 503-508.

(13) Luz, G. M.; Mano, J. F. Biomimetic Design of Materials and Biomaterials Inspired by the Structure of Nacre. Philos. Trans. R. Soc., A 2009, 367, 1587-1605.
(14) Kato, T. Polymer/Calcium Carbonate Layered Thin-Film Composites. Adv. Mater. 2000, 12, 1543-1546.

(15) Liu, L.; Jiang, J.; Yu, S.-H. Polymorph Selection and Structure Evolution of $\mathrm{CaCO}_{3}$ Mesocrystals under Control of Poly(Sodium 4Styrenesulfonate): Synergetic Effect of Temperature and Mixed Solvent. Cryst. Growth Des. 2014, 14, 6048-6056.

(16) Chen, S. F.; Yu, S. H.; Wang, T. X.; Jiang, J.; Cölfen, H.; Hu, B.; $\mathrm{Yu}, \mathrm{B}$. Polymer-Directed Formation of Unusual $\mathrm{CaCO}_{3}$ Pancakes with Controlled Surface Structures. Adv. Mater. 2005, 17, 1461-1465.

(17) Oaki, Y.; Imai, H. Hierarchically Organized Superstructure Emerging from the Exquisite Association of Inorganic Crystals, Organic Polymers, and Dyes: A Model Approach Towards Suprabiomineral Materials. Adv. Funct. Mater. 2005, 15, 1407-1414.

(18) Wang, T.; Cölfen, H.; Antonietti, M. Nonclassical Crystallization: Mesocrystals and Morphology Change of $\mathrm{CaCO}_{3}$ Crystals in the Presence of a Polyelectrolyte Additive. J. Am. Chem. Soc. 2005, $127,3246-3247$

(19) Zhang, X.; Huang, F.; Shen, Y.; Xie, A.; Lin, Z. Biomimetic Growth of $\mathrm{CaCO}_{3}$ Pancakes on the Leaves of Epipremnum Aureum. Russ. J. Phys. Chem. A 2011, 85, 2187-2191.

(20) Li, M.; Lebeau, B.; Mann, S. Synthesis of Aragonite Nanofilament Networks by Mesoscale Self-Assembly and Transformation in Reverse Microemulsions. Adv. Mater. 2003, 15, 20322035.

(21) Zhang, Q.; Ren, L.; Sheng, Y.; Ji, Y.; Fu, J. Control of Morphologies and Polymorphs of $\mathrm{CaCO}_{3}$ via Multi-Additives System. Mater. Chem. Phys. 2010, 122, 156-163.

(22) Gong, H.; Pluntke, M.; Marti, O.; Walther, P.; Gower, L.; Cölfen, H.; Volkmer, D. Multilayered $\mathrm{CaCO}_{3} /$ Block-Copolymer Materials via Amorphous Precursor to Crystal Transformation. Colloids Surf., A 2010, 354, 279-283.

(23) Zheng, L.; Hu, Y.; Ma, Y.; Zhou, Y.; Nie, F.; Liu, X.; Pei, C. Egg-White-Mediated Crystallization of Calcium Carbonate. J. Cryst. Growth 2012, 361, 217-224.

(24) Wang, T.; Leng, B.; Che, R.; Shao, Z. Biomimetic Synthesis of Multilayered Aragonite Aggregates Using Alginate as Crystal Growth Modifier. Langmuir 2010, 26, 13385-13392.

(25) Volkmer, D.; Harms, M.; Gower, L.; Ziegler, A. Morphosynthesis of Nacre-Type Laminated $\mathrm{CaCO}_{3}$ Thin Films and Coatings. Angew. Chem. Int. Ed. 2005, 44, 639-644.

(26) Gao, Y.-X.; Yu, S.-H.; Guo, X.-H. Double Hydrophilic Block Copolymer Controlled Growth and Self-Assembly of $\mathrm{CaCO}_{3}$ Multilayered Structures at the Air/Water Interface. Langmuir 2006, $22,6125-6129$.

(27) Oaki, Y.; Imai, H. The Hierarchical Architecture of Nacre and Its Mimetic Material. Angew. Chem. Int. Ed. 2005, 44, 6571-6575.

(28) Kahr, B.; Gurney, R. W. Dyeing Crystals. Chem. Rev. 2001, 101, 893-952.

(29) Kahr, B.; Shtukenberg, A. G. Dyeing Crystals since 2000. CrystEngComm 2016, 18, 8988-8998.

(30) Shtukenberg, A. G.; Ward, M. D.; Kahr, B. Crystal Growth with Macromolecular Additives. Chem. Rev. 2017, 117, 14042-14090.

(31) Xu, A.-W.; Ma, Y.; Cölfen, H. Biomimetic Mineralization. J. Mater. Chem. 2007, 17, 415-449.

(32) Song, R.-Q.; Cölfen, H. Additive Controlled Crystallization. CrystEngComm 2011, 13, 1249-1276.

(33) Ge, S. B.; Liu, C.; Wu, G. Synthesis, Structure, Photoluminescence Property of a Barium Complex With Sulfosalicylic Acid Ligand. Synth. React. Inorg., Met.-Org., Nano-Met. Chem. 2015, 45, $122-126$

(34) Zhu, Z.-B.; Wan, W.; Deng, Z.-P.; Ge, Z.-Y.; Huo, L.-H.; Zhao, H.; Gao, S. Structure Modulations in Luminescent Alkaline Earth Metal-Sulfonate Complexes Constructed from Dihydroxyl-1,5-Benzenedisulfonic Acid: Influences of Metal Cations, Coordination Modes and PH Value. CrystEngComm 2012, 14, 6675-6688.

(35) Lander, J. J. Polymorphism and Anion Rotational Disorder in the Alkaline Earth Carbonates. J. Chem. Phys. 1949, 17, 892-901. 
(36) Zaoui, A.; Shahrour, I. Molecular Dynamics Study of HighPressure Polymorphs of BaCO3. Philos. Mag. Lett. 2010, 90, 689697.

(37) Hlabela, P.; Maree, J.; Bruinsma, D. Barium Carbonate Process for Sulphate and Metal Removal from Mine Water. Mine Water Environ. 2007, 26, 14-22.

(38) Bosman, D. J.; Clayton, J. A.; Maree, J. P.; Adlem, C. J. L. Removal of Sulphate from Mine Water with Barium Sulphide. Int. J. Mine Water 1990, 9, 149-163.

(39) Castillo, J.; Gomez-Arias, A.; Posthumus, J.; Welman-Purchase, M.; Van Heerden, E. Geochemical Study of the Interaction of Acid and Alkaline Mine Drainage with $\mathrm{BaCO}_{3}$. Proceedings of the 10th International Conference on Acid Rock Drainage \& IMWA Annual Conference, Paper, 2015; Vol. 290.

(40) Torres, E.; Lozano, A.; Macías, F.; Gomez-Arias, A.; Castillo, J.; Ayora, C. Passive Elimination of Sulfate and Metals from Acid Mine Drainage Using Combined Limestone and Barium Carbonate Systems. J. Clean. Prod. 2018, 182, 114-123.

(41) Maree, J. P.; Hlabela, P.; Nengovhela, R.; Geldenhuys, A. J.; Mbhele, N.; Nevhulaudzi, T.; Waanders, F. B. Treatment of Mine Water for Sulphate and Metal Removal Using Barium Sulphide. Mine Water Environ. 2004, 23, 195-203.

(42) Properties and Applications of Witherite. Nature 1940, 146, 457-458, DOI: 10.1038/146457d0.

(43) Chen, S.-F.; Zhu, J.-H.; Jiang, J.; Cai, G.-B.; Yu, S.-H. PolymerControlled Crystallization of Unique Mineral Superstructures. Adv. Mater. 2010, 22, 540-545.

(44) Yu, S.-H.; Cölfen, H.; Tauer, K.; Antonietti, M. Tectonic Arrangement of $\mathrm{BaCO}_{3}$ Nanocrystals into Helices Induced by a Racemic Block Copolymer. Nat. Mater. 2004, 4, 51-55.

(45) Li, W.; Sun, S.; Yu, Q.; Wu, P. Controlling the Morphology of $\mathrm{BaCO}_{3}$ Aggregates by Carboxymethyl Cellulose through Polymer Induced Needle-Stacking Self-Assembly. Cryst. Growth Des. 2010, 10, 2685-2692.

(46) Lv, S.; Li, P.; Sheng, J.; Sun, W. Synthesis of Single-Crystalline $\mathrm{BaCO}_{3}$ Nanostructures with Different Morphologies via a Simple PVP-Assisted Method. Mater. Lett. 2007, 61, 4250-4254.

(47) Lv, S.; Sheng, J.; Zhang, S.; Sun, W. Effects of Reaction Time and Citric Acid Contents on the Morphologies of $\mathrm{BaCO}_{3}$ via PVPAssisted Method. Mater. Res. Bull. 2008, 43, 1099-1105.

(48) Qi, L.; Ma, J.; Cheng, H.; Zhao, Z. Reverse Micelle Based Formation of $\mathrm{BaCO}_{3}$ Nanowires. J. Phys. Chem. B 1997, 101, 3460.

(49) Wang, T.; Mitchell, J.; Börner, H.; Cölfen, H.; Antonietti, M. $\mathrm{BaCO}_{3}$ Mesocrystals: New Morphologies Using Peptide-Polymer Conjugates as Crystallization Modifiers. Phys. Chem. Chem. Phys. 2010, 12, 11984-11992.

(50) Zhu, J.-H.; Yu, S.-H.; Xu, A.-W.; Cölfen, H. The Biomimetic Mineralization of Double-Stranded and Cylindrical Helical $\mathrm{BaCO}_{3}$ Nanofibres. Chem. Commun. 2009, 1106.

(51) Li, L.; Chu, Y.; Liu, Y.; Dong, L.; Huo, L.; Yang, F. Microemulsion-Based Synthesis of $\mathrm{BaCO}_{3}$ Nanobelts and Nanorods. Mater. Lett. 2006, 60, 2138-2142.

(52) Zhu, W.; Cai, C.; Lin, J.; Wang, L.; Chen, L.; Zhuang, Z. Polymer Micelle-Directed Growth of $\mathrm{BaCO}_{3}$ Spiral Nanobelts. Chem. Commun. 2012, 48, 8544-8546.

(53) Shen, D.; Li, W.; Xu, S.; Wu, P. Fabrication of $\mathrm{BaCO}_{3}$ Sheaves Tailored by Carboxymethyl Cellulose under Compressed $\mathrm{CO}_{2}$. J. Cryst. Growth 2012, 353, 101-107.

(54) Chen, L.; Jiang, J.; Bao, Z.; Pan, J.; Xu, W.; Zhou, L.; Wu, Z.; Chen, X. Synthesis of Barium and Strontium Carbonate Crystals with Unusual Morphologies Using an Organic Additive. Russ. J. Phys. Chem. A 2013, 87, 2239-2245.

(55) Ma, X.; Su, C.; Yang, L.; Li, L.; Wang, K.; Zhou, J.; Yuan, S. Size- and Morphology-Controlled Biomimetic Synthesis of Hierarchical Hollow $\mathrm{BaCO}_{3}$. CrystEngComm 2012, 14, 8554-8561.

(56) Xu, S.; Ye, Z.; Wu, P. Biomimetic Controlling of $\mathrm{CaCO}_{3}$ and $\mathrm{BaCO}_{3}$ Superstructures by Zwitterionic Polymer. ACS Sustain. Chem. Eng. 2015, 3, 1810-1818.
(57) Yu, S.-H.; Cölfen, H.; Xu, A.-W.; Dong, W. Complex Spherical $\mathrm{BaCO}_{3}$ Superstructures Self-Assembled by a Facile Mineralization Process under Control of Simple Polyelectrolytes. Cryst. Growth Des. 2004, 4, 33-37.

(58) Shtukenberg, A. G.; Punin, Y. O.; Gunn, E.; Kahr, B. Spherulites. Chem. Rev. 2011, 112, 1805-1838.

(59) Shan, W.; Wang, B.; Zhang, Y.-H.; Wu, B.-Y.; Tang, Y. Fabrication of Calcium Carbonate with Exquisite Morphologies and Colors through a New Controlled Precipitation Approach. Chem. Lett. 2004, 33, 1248-1249.

(60) Schenk, A. S.; Zlotnikov, I.; Pokroy, B.; Gierlinger, N.; Masic, A.; Zaslansky, P.; Fitch, A. N.; Paris, O.; Metzger, T. H.; Cölfen, H.; et al. Hierarchical Calcite Crystals with Occlusions of a Simple Polyelectrolyte Mimic Complex Biomineral Structures. Adv. Funct. Mater. 2012, 22, 4668-4676.

(61) Mann, S.; Archibald, D. D.; Didymus, J. M.; Douglas, T.; Heywood, B. R.; Meldrum, F. C.; Reeves, N. J. Crystallization at Inorganic-Organic Interfaces: Biominerals and Biomimetic Synthesis. Science 1993, 261, 1286-1292.

(62) De Yoreo, J. J.; Vekilov, P. G. Principles of Crystal Nucleation and Growth. Rev. Mineral. Geochem. 2003, 54, 57-94.

(63) Li, L.; Fijneman, A. J.; Kaandorp, J. A.; Aizenberg, J.; Noorduin, W. L. Directed Nucleation and Growth by Balancing Local Supersaturation and Substrate/Nucleus Lattice Mismatch. Proc. Natl. Acad. Sci. U.S.A. 2018, 115, 3575-3580.

(64) Noorduin, W. L.; Grinthal, A.; Mahadevan, L.; Aizenberg, J. Rationally Designed Complex, Hierarchical Microarchitectures. Science 2013, 340, 832-837.

(65) Zhao, N.; Qi, L. Low-temperature Synthesis of Star-shaped PbS Nanocrystals in Aqueous Solutions of Mixed Cationic/Anionic Surfactants. Adv. Mater. 2006, 18, 359-362.

(66) Yang, D.; Qi, L.; Ma, J. Well-Defined Star-Shaped Calcite Crystals Formed in Agarose Gels. Chem. Commun. 2003, 1180-1181.

(67) Libbrecht, K. G. The Physics of Snow Crystals. Rep. Prog. Phys. 2005, 68, 855-895.

(68) Imai, H. Self-Organized Formation of Hierarchical Structures. Biomineralization I; Springer: Berlin, Heidelberg, 2006; pp 43-72.

(69) We note that the $\mathrm{p} K_{\mathrm{a}}$ of the dye at 11.4 might affect the crystal growth. ${ }^{70,71}$ This could be in form of a buffering mechanism or the preferential incorporation of the deprotonated form of the dye into the growing structures, which both could also enhance the apparent periodicity of the blocking effect.

(70) Bandara, J.; Mielczarski, J. A.; Kiwi, J. 1. Molecular Mechanism of Surface Recognition. Azo Dyes Degradation on $\mathrm{Fe}, \mathrm{Ti}$, and $\mathrm{Al}$ Oxides through Metal Sulfonate Complexes. Langmuir 1999, 15, $7670-7679$.

(71) Sabnis, R. W. Handbook of Biological Dyes and Stains: Synthesisand Industrial Applications; Wiley-Blackwell, 2010.

(72) Wang, R. Z.; Suo, Z.; Evans, A. G.; Yao, N.; Aksay, I. A. Deformation Mechanisms in Nacre. J. Mater. Res. 2001, 16, 24852493.

(73) Schäffer, T. E.; Ionescu-Zanetti, C.; Proksch, R.; Fritz, M.; Walters, D. A.; Almqvist, N.; Zaremba, C. M.; Belcher, A. M.; Smith, B. L.; Stucky, G. D.; et al. Does Abalone Nacre Form by Heteroepitaxial Nucleation or by Growth through Mineral Bridges? Chem. Mater. 1997, 9, 1731-1740.

(74) Schoeppler, V.; Lemanis, R.; Reich, E.; Pusztai, T.; Gránásy, L.; Zlotnikov, I. Crystal Growth Kinetics as an Architectural Constraint on the Evolution of Molluscan Shells. Proc. Natl. Acad. Sci. U.S.A. 2019, 116, 20388-20397. 